\title{
ANÁLISE DA IMPLEMENTAÇÃO DO PROGRAMA MUNICÍPIO VERDE AZUL NO MUNICÍPIO DE ADAMANTINA
}

\author{
Luana Ferreira Pires ${ }^{1}$ \\ Mariana Mazeti de Lima ${ }^{2}$ \\ Bianca Kaori Nomoto Yoshimura ${ }^{3}$ \\ Angélica Góis Morales 4
}

\begin{abstract}
RESUMO
As políticas públicas ambientais emergem como fruto de eventos internacionais e, no Brasil, são caracterizadas por sua ação descentralizada, que estimula a instituição de legislações de âmbito estadual e municipal, a fim de atender com maior eficiência as necessidades locais, e convidar a comunidade a participar da gestão do meio ambiente, como propõe o Programa Município Verde Azul (PMVA), criado pelo governo do Estado de São Paulo em 2007. Diante disso, o objetivo deste estudo foi analisar de que forma ocorre a implementação do PMVA no município de Adamantina, tal como seu desempenho ambiental na execução das ações que correspondem às Diretivas Ambientais: Esgoto Tratado, Resíduos Sólidos e Biodiversidade. Como metodologia foi utilizada a pesquisa bibliográfica, em fontes secundárias, como forma de aferir a fundamentação teórica no que diz respeito às políticas públicas, especialmente o PMVA, e pesquisa a documental. Os resultados deste estudo apontaram que Adamantina realiza ações visando atingir os objetivos das diretivas analisadas, garantindo que o município alcance pontuação suficiente para ser certificado. Foi observado também que são poucas as pesquisas sobre a aplicação deste programa nos municípios, contudo, este tipo de avaliação se faz importante a medida que proporciona o acompanhamento do desempenho municipal, bem como permite socializar medidas que poderão ser adotadas em outros lugares, promovendo a redução impactos negativos causados ao meio ambiente.
\end{abstract}

PALAVRAS-CHAVE: Política Pública. Programa Município Verde Azul. Meio Ambiente.

\footnotetext{
${ }^{1}$ Acadêmica do curso de Administração, Universidade Estadual Paulista - UNESP. luanaf.p@hotmail.com.

${ }^{2}$ Acadêmica do curso de Administração, Universidade Estadual Paulista - UNESP. mari_mazeti@hotmail.com.

${ }^{3}$ Acadêmica do curso de Administração, Universidade Estadual Paulista - UNESP. bianca.yoshimura@gmail.com.

${ }^{4}$ Orientadora. Doutora em Meio Ambiente e Desenvolvimento, Universidade Federal do Paraná UFPR, Pesquisadora e docente do Curso de Administração, Universidade Estadual Paulista UNESP. angelica@tupa.unesp.br.
} 


\title{
REVIEW OF THE IMPLEMENTATION OF CITY PROGRAM GREEN BLUE ON ADAMANTINA COUNTY
}

\begin{abstract}
As Environmental Public Policy emerge How Events International and fruit in Brazil are characterized by their decentralized action, that stimulates an institution of legislation in state and local Scope, an End to meet with Greater Efficiency Requirements as local, and invite the Community participate of Environmental Management, as proposed by the Green City Blue Program (PMVA), hair created Government of São Paulo in 2007. Thus, the aim of this study was to analyze in order que occurs PMVA Implementation make any municipality of Adamantina such As Your Environmental Performance in the executions of Shares corresponding to the Environmental Policy: Treated Sewage, Solid Waste and Biodiversity. As methodology used was the bibliographical research in secondary sources, as a way to measure the Theoretical Foundation not with regard to public policies, especially the PMVA, and documentary research. In this study the results showed que Adamantina Performs actions aimed at achieving the objectives of the analyzed policies, ensuring That the municipality range score Enough To Be certificate. Also was observed que Few as Research on the Application of this program nos municipalities, however, this type of evaluation is What Makes an Important Measure provides the monitoring of municipal Performance As Well As allows socializing measures may que ser adopted Page Other MS Places, promoting a Negative Impacts Reduction caused the Environment.
\end{abstract}

KEYWORDS: Public Policy. City Program Green Blue. Environment.

\section{EXAMEN DE LA APLICACIÓN DEL PROGRAMA DEL CONDADO DE VERDE AZUL EN EL CONDADO ADAMANTINA}

\begin{abstract}
RESUMEN
Las políticas ambientales surgen como resultado de los acontecimientos internacionales y, en Brasil, se caracterizan por su acción descentralizada, que estimula la creación de legislación estatal y municipal con el fin de atender con mayor eficacia a las necesidades locales, e invitan a la comunidad participar en la gestión ambiental, según lo propuesto por el Programa de Ciudad Verde azul (PMVA), creado por el gobierno del Estado de São Paulo en 2007. Por lo tanto, el objetivo de este estudio fue analizar cómo es la implementación de PMVA en el municipio de Adamantina como su desempeño ambiental en la ejecución de iniciativas que cumplen con la Política Ambiental: aguas residuales tratadas, residuos sólidos y de la Biodiversidad. La metodología utilizada fue la investigación bibliográfica, fuentes secundarias, como una forma de medir la base teórica con respecto a las políticas públicas, en especial el PMVA, y buscar en el documento. Los resultados de este estudio muestran que Adamantina realiza acciones encaminadas a la consecución de los objetivos de las políticas analizadas, lo que garantiza que la puntuación alcance municipio suficiente para ser certificado. También se observó que hay poca investigación sobre la aplicación de este programa en las ciudades, sin embargo, este tipo de evaluación es importante, ya que proporciona el monitoreo del desempeño municipal y permite medidas socializadoras que podrían adoptarse en otros lugares, la promoción reducir los impactos negativos al medio ambiente.
\end{abstract}

PALABRAS CLAVE: Política Pública. Programa Azul Verde Ciudad. Medio Ambiente. 


\section{Periódica Eletrônica \\ Fórum Ambiental}

da Alta Paulista
Volume 11, Número 07, 2015

Politicas Públicas e a Proteção do Meio Ambiente

\section{INTRODUÇÃO}

Historicamente, as políticas eram orientadas ao incentivo do desenvolvimento industrial das cidades, mas as novas demandas exigiram outros direcionamentos para a formulação desses instrumentos, como a problemática ambiental. Ela emergiu e tornou-se uma das prioridades na agenda brasileira por meio das reivindicações da sociedade que requer do governo ações mitigadoras dos impactos das atividades humanas sobre o meio ambiente e estabelecimento de um novo modelo social (SALHEB et al., 2009).

Salheb et al. (2009) atribui ao governo de Getúlio Vargas o nascimento da política ambiental no Brasil, com a adesão ao Código das Águas, Código de Minas e Código Florestal, em 1934 e, a criação do Parque Nacional de Itatiaia e da lei de proteção ao patrimônio histórico e artístico nacional, em 1937. Nessa época a preocupação das políticas estava na utilização racional dos recursos naturais, bem como na limitação da extensão da propriedade privada para estabelecimento de áreas de preservação permanente. Contudo, em detrimento das legislações promulgadas, para o poder público a prioridade era o desenvolvimento econômico por meio do crescimento industrial.

Dessa forma, as políticas públicas ambientais surgem efetivamente como resultado de grandes eventos internacionais responsáveis por disseminar conceitos que tornaram-se metas governamentais, como o desenvolvimento sustentável. Esse foi consolidado legalmente em 1981 com a Política Nacional de Meio Ambiente (Lei 6.938/81), que previu pela primeira vez, uma possível harmonização de crescimento econômico e respeito ao meio ambiente. Essa mesma lei instituiu o Sistema Nacional de Meio Ambiente, integrado pelo Conselho Nacional do Meio Ambiente (CONAMA) (BARBOSA; GOLDEMBERG, 2004; SALHEB et al., 2009).

No entanto, a gestão pública brasileira, em matéria de meio ambiente, é qualificada como atípica por Barbosa e Goldemberg (2004) por sua ação descentralizada, fortalecedora das esferas estadual e municipal, que criam suas próprias políticas públicas ambientais em busca de maior atuação da administração local e participação social, a fim de alcançar eficiência na gestão do meio ambiente. Esse é o objetivo do Programa Município Verde Azul (PMVA) criado pelo governo de São Paulo em 2007 e que hoje conta com a adesão de 645 municípios, dentre eles Adamantina, segundo os dados da Secretaria do Meio Ambiente do Estado de São 
Paulo.

Considerando que o município de Adamantina aparece no ranking do PMVA desde o ano de 2008, essa pesquisa é justificada pela necessidade de acompanhamento das ações municipais para a legítima eficácia do programa e pela escassez de trabalhos que avaliem a aplicação local dessa política e possam gerar ação social. Sendo assim, espera-se responder o seguinte problema: Qual o desempenho do município de Adamantina no Programa Município Verde Azul?

\subsection{O PROGRAMA MUNICÍPIO VERDE AZUL}

Em 2007, 21 Projetos Ambientais Estratégicos, conhecidos como certificações ou selos ambientais, foram elaborados pela Secretaria Meio Ambiente (SMA) do Estado de São Paulo. Esse conjunto integrava o Projeto Município Verde, que posteriormente, mediante reconhecimento da sua contribuição com a gestão hídrica municipal, incorporou a palavra "Azul". No entanto, sua consolidação enquanto programa aconteceu apenas em 2011, quando a SMA trouxe uma nova proposta para a abordagem das temáticas ambientais por meio de programas (KONRAD, 2014; GIRÃO, 2012).

Hoje, sob nome de Programa Município Verde Azul (PMVA), essa política pública de responsabilidade de elaboração e coordenação da Secretaria de Estado do Meio Ambiente, tem o objetivo principal de ganhar eficiência na gestão ambiental por meio de estímulos e capacitações para as prefeituras do estado de São Paulo, com o intuito destas implementarem uma agenda ambiental estratégica (SÃO PAULO, 2015).

As etapas do ciclo do programa estão ilustradas na Figura 1.

Figura 1: Passo a Passo do Programa Município Verde Azul

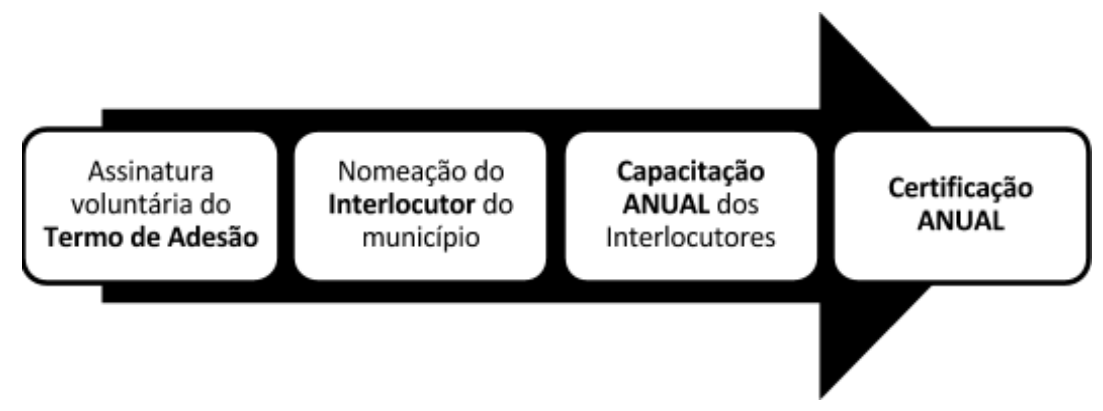


Fonte: GIRÃO, 2012.

Conforme indicada na Figura 1, a primeira etapa envolve a adesão voluntária do município ao PMVA, oficializada pelo Termo de Adesão assinado pelo chefe do poder executivo municipal, com o testemunho de no mínimo um vereador e um representante da sociedade civil. Esse procedimento é seguido da nomeação, realizada pelo prefeito, do Interlocutor e do Suplente que, segundo a resolução no 26 de 2015 do programa, deverão ser agentes públicos do quadro da prefeitura e serão os únicos a trabalhar junto à equipe do programa, embora seja encargo de toda repartição apoiar na consecução das ações ambientais.

A resolução atribui à SMA, a responsabilidade de orientar o planejamento ambiental municipal, o cumprimento adequado das diretivas, e a utilização e preenchimento do Sistema Informatizado do Programa e, dessa forma, ocorre anualmente capacitação para os Interlocutores. Segundo Girão (2012), nessa capacitação são apresentados detalhadamente os critérios utilizados para avaliar e pontuar a gestão ambiental do município a partir das 10 diretivas do programa: Esgoto Tratado, Resíduos Sólidos, Biodiversidade, Arborização Urbana, Educação Ambiental, Cidade Sustentável, Gestão das Águas, Qualidade do Ar, Estrutura Ambiental e Conselho Ambiental. As características dessas diretivas podem ser observadas no Anexo 1.

Cabe a Secretaria do Meio Ambiente estabelecer e divulgar anualmente os critérios, pesos e notas das Diretivas Ambientais para a aplicação do IAA. Até o ano de 2013, as Diretivas eram compostas por dois conjuntos de ações: as consideradas prioritárias, constituintes dos Indicadores de Desempenho (ID), e as que auxiliavam o atendimento das prioritárias e valorizam a predisposição cultural dos municípios, denominadas Pró-atividades (PRÓ). A partir de 2014, tem-se observado apenas as ações integrantes dos Indicadores de Desempenho (SÃO PAULO, 2015).

Esses dados dão suporte para que a prefeitura elabore seu Planejamento Ambiental e desenvolva ações a fim de cumprir as Diretivas estabelecidas. A partir disso, é gerado o Relatório de Gestão Ambiental que, com os respectivos arquivos comprovantes digitais, é enviado para o Sistema Informatizado do Programa, encerrando então a quarta etapa ilustrada na Figura 1. É importante ressaltar que as informações e os documentos disponibilizados pelos municípios são passíveis de auditoria. 
Por meio da análise desse relatório e de dados do Sistema Ambiental do Estado de São Paulo, a equipe do programa inicia o processo de avaliação das ações realizadas em cada município signatário aplicando a fórmula do índice de Avaliação Ambiental (IAA):

$$
I A A=\Sigma I D i-P P
$$

$\Sigma I D i$ - é o somatório, de no máximo 100 pontos, dos Indicadores de Desempenho (IDi) das Diretivas Ambientais do Programa, sendo que cada uma delas é identificada pelo índice i equivalente a uma nota que varia de 0 a $10 \mathrm{e}$, posteriormente, é ajustada ao peso da Diretiva a qual corresponde, conforme indicado no Anexo 2.

PP - São passivos e/ou pendências de incumbência municipal de origem legislativa, no que toca dívidas ambientais não extintas pela prefeitura, e de obrigações relacionadas a coleta e tratamento de esgoto e aterros sanitários. Podem ser atribuídos até 20 pontos ao primeiro caso e até 10 ao segundo, totalizando o máximo de 30 pontos de passivo.

A avaliação e pontuação do relatório ocorre através da verificação dos arquivos exclusivamente digitais, de forma que esses precisam ser cópias fiéis do documento original, sem rasuras ou alterações que prejudiquem sua qualidade. Ademais, devem ser compatíveis com o Programa Office 2007 e gravados em CD, DVD ou Pen Drive posteriormente protocolizado na secretaria do PMVA ou enviado por correio até a data do fechamento do Sistema Informatizado.

Todo ano é avaliada a eficácia dos municípios participantes na execução das atividades propostas na agenda. Posteriormente, é disponibilizado à Secretaria Estadual do Meio Ambiente, às prefeituras e à população o Indicador de Avaliação Ambiental. E por fim, a SMA concede anualmente o Ranking Ambiental dos municípios paulistas em que há três categorias e premiações para cada uma delas.

A participação no PMVA é pré-requisito para a liberação de recursos do Fundo Estadual de Controle da Poluição (FECOP). Neste, são disponibilizados recursos para melhorar as ações ambientais no que se refere principalmente aos resíduos. Tais recursos podem ser equipamentos para aterros sanitários, caminhões de coleta seletiva, centros de triagem, entre outros (FREGONESI, 2010). 
Segundo a SMA (2015), os municípios que atingirem um Índice de Avaliação Ambiental de 80 pontos ou mais, receberão o Certificado Município Verde Azul, da Secretaria de Estado do Meio Ambiente, que declara a competência municipal na execução das ações orientadas às diretivas do programa. Contudo, ainda são requisitos para a certificação:

a) Conselho Municipal de Meio Ambiente e Estrutura Executiva Ambiental amparados por lei, bem como implementação da última.

b) Pontuação igual ou superior a 7,1 no Índice de Qualidade de Aterro de Resíduos, calculado pela Companhia Ambiental do Estado de São Paulo (CETESB).

c) Diretiva "Esgoto Tratado" com pontuação igual ou superior a 6 na soma das notas dos Indicadores de Desempenho.

d) Atingir pontuação superior a $0 \mathrm{em}$ todas as diretivas.

e) Irregularidades ou inveracidade nos documentos e nas informações fornecidas provocam perda de pontos ou do certificado.

Além do certificado, a Secretaria informa que os municípios e parceiros concorrem aos prêmios: Prêmio Anual aos Interlocutores, Prêmio Governador André Franco Montoro e Interlocutores, e Prêmio Parceria Verde Azul. A primeira premiação é designada aos Interlocutores que mais se destacaram no desempenho das ações orientadas às diretivas do projeto.

O Prêmio Governador André Franco Montoro, leva o nome que faz referência ao ex-governador do estado, que apoiava a descentralização administrativa e, em 1983, criou o Conselho Estadual do Meio Ambiente (CONSEMA) que deu início a Secretaria de Estado. É contemplado com esse prêmio, o município ocupante da primeira posição em cada uma das 22 Unidades de Gerenciamento de Recursos Hídricos - UGRHI's de São Paulo, desde que atinja no mínimo 80 pontos no IAA (SÃO PAULO, 2015).

Por fim, o Prêmio Parceria Verde Azul se destina às iniciativas desenvolvidas para beneficiar ao meio ambiente, sejam de pessoa jurídica ou pessoa física, e que tenha parceria com o setor público estadual ou municipal. 


\section{OBJETIVOS}

\subsection{OBJETIVO GERAL}

Analisar de que forma ocorre a implementação do Programa Município Verde Azul no município de Adamantina, bem como seu desempenho ambiental na execução das ações que correspondem às Diretivas Ambientais: Esgoto Tratado, Resíduos Sólidos e Biodiversidade.

\subsection{OBJETIVOS ESPECÍFICOS}

- Caracterizar o Programa Município Verde Azul.

- Analisar o histórico de pontuação e a posição ocupada pelo município de Adamantina no ranking do Programa Município Verde Azul.

- Identificar quais são as ações adotadas pelo município de Adamantina para alcançar os objetivos estabelecidos nas Diretivas Ambientais Esgoto Tratado, Resíduos Sólidos e Biodiversidade, e de que forma a agenda municipal está sendo cumprida.

\section{METODOLOGIA}

Para o desenvolvimento desta pesquisa foi realizada pesquisa bibliográfica, em fontes secundárias, a fim de conferir embasamento teórico no que tange as políticas públicas, em particular, as ambientais. Após esse levantamento, a pesquisa se debruçou sobre o Programa Município Verde Azul, política pública ambiental do estado de São Paulo, e sua aplicação no município de Adamantina.

Por meio da pesquisa documental foram consultados o Relatório de Gestão Ambiental municipal de Adamantina, e as resoluções que amparam o PMVA, além de dados coletados mediante contato telefônico e por correio eletrônico, com os responsáveis pelo Programa Município Verde Azul da Secretaria do Meio Ambiente do município estudado. Foram reunidas também as informações disponíveis na própria página da Secretaria do Meio Ambiente do Governo do Estado de São Paulo, que traz todas as orientações e diretivas do PMVA.

Para este estudo, foram identificadas as ações realizadas no último ciclo do PMVA, do ano de 2014, a fim de atender os objetivos estabelecidos para três Diretivas Ambientais do programa: Esgoto Tratado, Resíduos Sólidos e Biodiversidade. Justifica-se a escolha dessas diretivas, pois em situação de empate 
entre o Índice de Avaliação Ambiental (IAA) de dois ou mais municípios, a posição no ranking é estabelecida pela nota atribuída a elas, na ordem em que se encontram.

A análise dos dados foi qualitativa, pois o enfoque principal foi avaliar o contexto socioambiental do município e identificar quais ações conferem a atual posição de Adamantina no ranking do programa comparando os Indicadores de Desempenho exigidos na Resolução SMA № 20, de 14 de março de 2014 e os atendidos, conforme indicado no Relatório de Gestão Ambiental. Nesse sentido, a interpretação do pesquisador dos fenômenos acerca do objeto de estudo foi uma característica relevante (MENGA; ANDRÉ, 1986).

\section{RESULTADOS}

\subsection{CARACTERIZAÇÃO DO MUNICÍPIO DE ADAMANTINA}

Em 1938, um ano após a Companhia de Agricultura, Imigração e Colonização (CAIC) ter iniciado o povoamento da região da Bacia Hidrográfica Aguapeí/Peixe, em que se encontra Adamantina, foi executado o plano de colonização que previa a fração de latifúndios em propriedades com área de 10 alqueires com acesso à água e estradas. Mais tarde, a construção da ferrovia, com término no município, incentivou o ingresso de pessoas e produção agrícola na região, proporcionando o seu desenvolvimento. Contudo, apenas em dezembro de 1948 foram estabelecidos o distrito e município de Adamantina (ADAMANTINA, 2015).

Atualmente, o município localizado, no bioma Mata Atlântica, abrange uma população residente de aproximadamente 33.797 habitantes, distribuídos em $411,987 \mathrm{~km}^{2}$ de área total, sendo que $52 \%$ do total de habitantes correspondem ao sexo feminino. Com um Índice de Desenvolvimento Municipal de 0,790, Adamantina tem uma economia sustentada em $76 \%$ pelos serviços, $19 \%$ pela indústrias e o restante pela agricultura (IBGE, 2015).

\subsection{ANÁLISE DE ADAMANTINA NO PROGRAMA MUNICÍPIO VERDE AZUL}

A partir do Índice de Avaliação Ambiental de cada município é montado um ranking geral do PMVA com todas as prefeituras que aderiram ao programa. Além dele, com o IAA, os municípios são classificados também mediante outros dois 
critérios: UGRHI e por faixa populacional. Dessa forma, em 2014, com a pontuação de 92,26, Adamantina foi rankeada no Programa Município Verde Azul, UGRHI e por faixa populacional, nas seguintes colocações, 20ำ $1^{\circ}$ (categoria: peixe) e $4^{\circ}$ (categoria: Municípios com população entre 20 e 50 mil habitantes), respectivamente.

O quadro 2 apresenta a evolução histórica da pontuação e posição de Adamantina no PMVA, entre os anos de 2008 a 2014 (SÃO PAULO, 2014).

\section{Quadro 2: Evolução Histórica da cidade de Adamantina em relação ao ranking do Programa Município Verde Azul}

\begin{tabular}{|l|l|l|l|l|l|l|l|}
\hline Ano & 2008 & 2009 & 2010 & 2011 & 2012 & 2013 & 2014 \\
\hline Nota & 82,36 & 80,95 & 80,28 & 85,51 & 90,6 & 83,3 & 92,26 \\
\hline Posição & $34^{\circ}$ & $144^{\circ}$ & $137^{\circ}$ & $79 \circ$ & $39 \circ$ & $42^{\circ}$ & $20^{\circ}$ \\
\hline
\end{tabular}

Nota-se que, a partir dos dados coletados de 2008 a 2014, Adamantina não apresentou grandes variações nos resultados do Índice de Avaliação Ambiental. Entretanto, houve uma queda significativa na posição ocupada pelo município de 2008 para 2009, explicada pelo aumento de participantes no programa, que eram 332 no primeiro ano e progrediu para 566. Além disso, cresceu também o número de certificados que, inicialmente, eram 44 e passaram a ser 168 na classificação de 2009.

Após essa queda, o município subiu na classificação do programa até o ano de 2013, em que desceu três posições, provavelmente devido a redução da pontuação. Contudo, recuperou-se em 2014 alcançando o 20 lugar, o mais alto conquistado por Adamantina desde sua adesão ao PMVA.

\subsection{ANÁLISE DAS AÇÕES ADOTADAS PARA CUMPRIMENTO DAS DIRETIVAS}

As ações adotadas pelo município de Adamantina, para o alcance das diretivas Esgoto Tratado, Resíduos Sólidos e Biodiversidade, no último ciclo do Programa Município Verde Azul, correspondente ano de 2014, foram analisadas com base nos Indicadores de Desempenho estabelecidos para avaliação de cada Diretiva Ambiental (Anexo 3, Anexo 4 e Anexo 5). 


\subsubsection{DIRETIVA 1: ESGOTO TRATADO}

Propiciar a coleta e tratamento de todo o esgoto gerado na zona urbana, assegurando qualidade de vida social e dos corpos hídricos, bem como preservação ambiental, foi o objetivo de Adamantina para a Diretiva Esgoto Tratado. Para tanto, ocorreu a recolha e a remoção de poluentes e microrganismos do esgoto, procedimento realizado pela Companhia de Saneamento Básico do Estado de São Paulo, bem como, foi aprovado em 2009 o Plano de Saneamento Ambiental Municipal que regulariza procedimentos pertinentes aos resíduos sólidos e drenagem e manejo de águas pluviais. São eles: coleta, transporte, triagem e destino final.

Foram realizados também os dois monitoramentos do desempenho das Estações de Tratamento de Esgoto (ETE), previstos nos Indicadores de Desempenho da diretiva, por meio da coleta de amostras, sendo que a primeira ocorreu em 21/05/2014 na Adamantina/ETE Oeste com resultados emitidos em 17/06/2014, e a segunda no dia 27/08/2014 na lagoa de tratamento Adamantina/ETE Leste, contudo, o prazo de fechamento do Sistema Informatizado do Programa se encerrou antes que fosse concluída a análise dessa coleta.

A elaboração do Relatório de Gestão Ambiental prevê o diagnóstico da situação atual do município, dessa forma, no que toca a Diretiva Esgoto Tratado, essa análise integra as estratégias, isso porque as medidas que visam alcançar o objetivo indicado já são adotadas em Adamantina. Ademais, a proposta municipal de $100 \%$ de coleta e tratamento do esgoto produzido na zona urbana já foi atendida, de forma que para esta diretiva não são realizadas ações além daquelas que são exigidas para a obtenção de pontuação, entretanto, no último ano, a segunda análise de desempenho da Estação de Tratamento de Esgoto (ETE), ocorrida na Adamantina/ETE Leste, não retornou resultados antes do prazo de encerramento do ciclo do Programa Município Verde Azul 2014. Contudo, esse Indicador de Desempenho garantiu a pontuação integral devido a realização do acompanhamento da coleta do esgoto.

Contudo, a aplicação do Indicador de Coleta de Tratabilidade de Esgoto da População Urbana de Município (ICTEM), de responsabilidade de cálculo e divulgação da CETESB, representa o indicador com maior peso nessa diretiva, 
sendo que a pontuação a ele atribuída varia entre 0 e 8 pontos, o que permitiu que Adamantina concorresse ao Certificado Município Verde Azul, lembrando que alcançar nota igual ou superior a 6 na Diretiva Esgoto Tratado é um pré-requisito para obter a certificação.

\subsubsection{DIRETIVA 2: RESÍDUOS SÓLIDOS}

Para a Diretiva Resíduos sólidos foram elencados cinco objetivos: a) Oferecer melhor qualidade de vida os habitantes por meio da coleta seletiva; b) Preservar o meio ambiente a partir da mitigação do impacto negativo oriundo da produção de resíduos sólidos; c) Conscientizar os habitantes da importância da administração dos resíduos sólidos; d) Oferecer melhores condições de saúde e trabalho para quem opera na cadeia de resíduos sólidos; e) Aumentar a durabilidade do aterro diminuindo a quantidade de lixo despejada, para que não seja necessário adquirir novas áreas.

Afim de atender esses objetivos, em 2012 foi instituído como lei o Plano Municipal de Resíduos Sólidos, no qual se integra o Plano de Resíduos de Construção Civil, bem como ocorreu o preenchimento do relatório de coleta seletiva, no qual constava a estimativa percentual de material reciclável recolhido, do questionário do Índice de Qualidade de Gestão de Resíduos, fornecido pelo Programa Município Verde Azul, e da Planilha de Monitoramento do Aterro, constituída de duas avaliações realizadas em 30/06/2014 e 08/08/2014, respectivamente.

Com relação às ações de recolha e destino de resíduos oriundo de pósconsumo, Adamantina contou com as seguintes iniciativas:

a) Destinação de pneus para a empresa Reciclanip;

b) Recepção de pneus do município de Flórida Paulista para armazenamento temporário e destinação em conjunto com a prefeitura de Adamantina;

c) Coleta e armazenamento de lâmpadas, lixo eletrônico e vidros de parabrisas;

d) Realização da Expo-Verde, evento tradicional do município em parceria com iniciativas privadas, que envolve população de toda a região. A troca do óleo, 
em parceria com o Rotary-Club, é uma das ações que acontecem dentro do evento, assim como a coleta de lixo eletrônico, o Mercado Solidário dentre outras.

e) Ação de conscientização sobre a coleta seletiva e divulgação das datas de coleta de lixo orgânico e inorgânico, no evento Expo-Verde.

Assim como em Esgoto Tratado, o diagnóstico da situação atual do município é uma estratégia na Diretiva Resíduos Sólidos, indicando a proposição de continuidade das medidas municipais já desenvolvidas.

Ao Índice de Qualidade de Aterro de Resíduos (IQR), de cálculo e divulgação de competência da CETESB, é atribuída pontuação que varia de 0 a 4 . Os demais Indicadores de Desempenho, de responsabilidade da prefeitura, foram atendidos, com destaque às "Ações de Responsabilidade Pós-Consumo com Setores Produtivos para Coleta e Destinação Adequada de Resíduos”, Indicador que totalizou cinco ações com parceria de empresas, como a Granol, e como município de Flórida Paulista. Adiante disso, Adamantina para além do cumprimento dos critérios, recebeu certificado da empresa Sterlix Ambiental Tratamento de Resíduos Ltda devido às atividades de coleta de resíduo hospitalar, e ainda recebeu solicitação da formalização do Estatuto/Contrato para que seja aberta a Associação de Catadores Recicláveis.

\subsubsection{DIRETIVA 3: BIODIVERSIDADE}

De acordo com a Relatório de Gestão Ambiental de Adamantina, para a Diretiva Biodiversidade os objetivos estabelecidos foram: a) Amparar e conduzir os proprietários de até quatro módulos fiscais (80 hectares) na realização do cadastro no Sistema de Cadastro Ambiental Rural do Estado de São Paulo (SICAR-SP); b) Incentivar a população a refletir e adquirir responsabilidade ambiental; c) Estimular a preservação dos animais silvestres mediante manutenção da fauna, prevenção e recuperação de danos à saúde animal.

Nesse sentido, foi realizada a demarcação da área de vegetação nativa de duas propriedades rurais destinadas ao estabelecimento de empreendimentos para fauna silvestre. Os próprios proprietários demonstraram interesse em demarca-las. Para esse fim, foram delineados os polígonos das propriedades, no Google Earth, identificando-as dentro do perímetro municipal. Ademais, elaborou-se uma planilha com os dados das propriedades e seus respectivos proprietários. 
da Alta Paulista
Volume 11, Número 07, 2015

Politicas Públicas e a Proteção do Meio Ambiente

A estratégia adotada por Adamantina para atender ao Indicador de Desempenho "Ação relacionada ao incentivo e ajuda ao proprietário rural para cadastro no Sistema de Cadastro Ambiental Rural do Estado de São Paulo (SICARSP)" foi a publicação e divulgação do Cadastro Ambiental Rural (CAR) nos jornais da cidade e região, orientando os proprietários a procurarem a Secretária de Agricultura, Abastecimento e Meio Ambiente, a fim de esclarecer dúvidas e efetuar o registro no sistema.

Outra ação do município foi a medida de recepção, destinação e manutenção de animais silvestres, foi realizado contato com a UNESP de Araçatuba-SP, que conta com um Centro de Recuperação e Triagem de Animais Silvestres (CERETAS). O principal objetivo da cidade em relação a este Centro está relacionado com os cuidados e manutenção dos animais silvestres. Para reforçar tal preocupação, há também ofícios do Corpo de Bombeiros e da polícia ambiental, em que a primeira informa as devidas ações que devem ser tomadas em relação aos animais silvestres, e a segunda informa qual o manejo realizado com estes animais em específico.

Ademais, consta no Relatório a participação em videoconferências que abordaram a Gestão da Fauna Silvestre e, na Capacitação de Agentes Públicos Municipais na área de Restauração Ecológica e Treinamento acerca do SICAR-SP.

\section{CONCLUSÃO}

O Programa Município Verde Azul foi concebido em 2007, visando tornar mais eficiente a gestão ambiental estadual por meio de ações descentralizadas previstas na Agenda Ambiental Estratégica desenvolvida pelos municípios que aderissem à política. Nesse sentido, após a análise das diretivas apontadas neste estudo, percebeu-se que a participação de Adamantina no PMVA favoreceu a adoção de ações socioambientais, a medida que ocorreu o emprego de iniciativas a fim de atender os critérios de avaliação estabelecidos para cada uma das Diretivas Ambientais.

O Relatório de Gestão Ambiental de Adamantina aponta a continuidade da realização de atividades que envolvem os Indicadores de Desempenho das diretivas Esgoto Tratado e Resíduos Sólidos, evidenciando que a participação constante no programa incentiva, consequentemente, o desenvolvimento sequencial das ações, 
para que elas sejam pontuadas a cada novo ciclo do PMVA. Ademais, na segunda diretiva citada, o município tem adotado práticas para além daquelas exigidas nos critérios de avaliação, de forma a ser beneficiado caso a composição das diretivas ainda contasse com as Pró-atividades.

$\mathrm{Na}$ diretiva Biodiversidade Adamantina também tem realizado as ações preconizadas nos respectivos Indicadores de Desempenho, e é possível afirmar que o mesmo ocorre com as demais sete diretivas, considerando o progresso do município no programa, fato confirmado pela posição ocupada no ranking (20ํำ colocado) e por ter sido contemplado nas três categorias passíveis de premiação em 2014.

Ações como as implementadas em Adamantina podem ser empregadas em outros municípios, conferindo importância aos estudos que, assim como este, socializam essas iniciativas de maneira a permitir que as mesmas sejam reproduzidas. Além disso, este tipo de pesquisa proporciona melhor compreensão sobre o Programa Município Verde Azul, dessa forma, foi possível perceber que a avaliação do programa é baseada na entrega de documentos comprobatórios, tornando interessante realizar fiscalizações nos municípios que atingirem pontuação suficiente para adquirir certificação, a fim de verificar a efetividade da realização das iniciativas e, avaliar e medir o quanto elas geram melhorias.

\section{REFERÊNCIAS BIBLIOGRÁFICAS}

ADAMANTINA. História da Cidade. Disponível em: <http://www.adamantina.sp.gov.br/portal/histcidade.jsp>. Acesso em: 21 maio 2015.

BARBOSA, L. M.; GOLDEMBERG, J. A legislação ambiental no Brasil e em São Paulo. Revista Eco 21, Ano XIV, Edição 96, Novembro 2004. Disponível

em:<http://www.eco21.com.br/textos/textos.asp?ID=954 >. Acesso em: 10 Abr. 2015.

FREGONESI, L. Convênios do FECOP são assinados por 126 municípios. 2010. Disponível em: <http://www.ambiente.sp.gov.br/blog/2010/03/31/convenios-do-fecop-sao-assinados-por-126municipios/>. Acesso em: 10 Abr. 2015

GIRÃO, R. J. O Programa Município Verde Azul e sua influência na gestão ambiental municipal no estado de São Paulo. 2012. 112 p. Dissertação (Mestrado em Ciências) - Universidade de São Paulo. Piracicaba, 2012.

GOVERNO DO ESTADO DE SÃO PAULO - SISTEMA AMBIENTAL PAULISTA. Município Verde

Azul. Disponível em: <http://www.ambiente.sp.gov.br/municipioverdeazul/>. Acesso em: 10 Abr. 2015 
INSTITUTO BRASILEIRA DE GEOGRAFIA E ESTATÍSTICA - IBGE. Adamantina. Disponível em: <http://www.cidades.ibge.gov.br/xtras/perfil.php?lang=\&codmun=350010\&search=||infogr\%E1ficos:informa\%E7\%F5es-completas>. Acesso em: 21 maio 2015.

KONRAD, E. C. G. Políticas de apoio a gestão da arborização urbana: uma análise do Programa Município Verde Azul. 2014. 161 f. Tese (Doutorado em Agronomia)- Universidade Estadual Paulista. Ilha Solteira, 2014.

MENGA, L.; ANDRÉ, M. E. D. A. Pesquisa em educação: abordagens qualitativas. São Paulo: EPU, 1986.

SALHEB, G. J. M. et al. Políticas públicas e meio ambiente: reflexões preliminares. Planeta Amazônia: Revista Internacional de Direito Ambiental e Políticas Públicas, 2009, Vol. 1. № 1. p. 0527.

SÃO PAULO (Estado). Secretaria do Meio Ambiente. PMVA 2013 Manual de instruções. Programa Município Verde Azul. 2013. Disponível em <http://www.ambiente.sp.gov.br/pactodasaguas/files/2011/05/Manual_PMVA_2013_2.pdf>.Acesso em: 01 maio 2015.

SÃO PAULO (Estado). Secretária de Estado do Meio Ambiente. Resolução no 20, de 14 de março de 2014. Estabelece os parâmetros para avaliação dos Relatórios de Gestão Ambiental Municipais para o exercício de 2014, no âmbito do Programa Município Verde Azul, e dá providências correlatas.

Diário Oficial [do] Estado de São Paulo, 15 de março de 2014. Seção 1, p. 97-98. 2014a.

Disponível em: <http://www.ambiente.sp.gov.br/legislacao/files/2014/03/RESOLUCAO-SMA-N-20-DE14-DE-MARCO-DE-2014.pdf>. Acesso em: 01 maio 2015.

SÃO PAULO (Estado). Secretária de Estado do Meio Ambiente. Resolução SMA № 53, de 13 de Junho de 2014. Altera os parâmetros para avaliação da Diretiva Biodiversidade no Relatório de Gestão Ambiental - RGA, no âmbito do Programa Município Verde Azul, para o exercício de 2014. Diário Oficial [do] Estado de São Paulo, 14 de junho de 2014. Seção 1, p. 41-42. 2014b. Disponível em: <http://www.ambiente.sp.gov.br/legislacao/resolucoes-sma/resolucao-sma-53-2014/>. Acesso em: 01 maio 2015.

SÃO PAULO (Estado). Secretária de Estado do Meio Ambiente. Resolução oㅜ 26, de 28 de abril de 2015. Estabelece procedimentos operacionais e parâmetros de avaliação no âmbito do Programa Município Verde Azul, para o exercício de 2015, e revoga as Resoluções correlatas. Diário Oficial [do] Estado de São Paulo, 29 de abril de 2015. Seção 1, p. 55-59. Disponível em: <http://www.ambiente.sp.gov.br/municipioverdeazul/files/2015/04/Resolu\%C3\%A7\%C3\%A3o-SMA26_2015_PMVA.pdf >. Acesso em: 01 maio 2015.

SECRETARIA DO MEIO AMBIENTE (SMA). O programa. Disponível em: <http://www.ambiente.sp.gov.br/municipioverdeazul/o-projeto/>. Acesso em : 9 abr. 2015.

SOUZA, C. Políticas públicas: uma revisão da literatura. Sociologias. Ano $8, n^{\circ} 16$, jul/dez 2006, p. 20-45. Disponível em: <http://www.scielo.br/pdf/soc/n16/a03n16>. Acesso em: 9 abr. 2015. 